\title{
CONTRIBUIÇÕES PARA UM ANTEPROJETO DE ARQUITETURA DE UMA INSTITUIÇÃO DE LONGA PERMANÊNCIA PARA IDOSOS (ILPI), EM SÃO JOSÉ DE PIRANHAS-PB
}

\author{
CONTRIBUTIONS TO A DRAFT ARCHITECTURE OF A LONG-TERM \\ PERMANENT INSTITUTION (ILPI) IN SAO JOSÉ DE PIRANHAS-PB
}

\author{
Hildevando Leite Dantas ${ }^{1}$ \\ Emanoella Bella Sarmento Salgueiro Eliziário Matias ${ }^{2}$ \\ André Ferreira Costa ${ }^{3}$ \\ Melina Cavalcanti de Melo Bichino ${ }^{4}$ \\ Janderson Ferreira Dutra ${ }^{5}$ \\ Isabel Sobral de Abreu e Lima ${ }^{6}$
}

RESUMO: Objetivo: Analisar a situação atual dos idosos que necessitam de uma alternativa de lugar para viver, bem como entender como as ILPIs podem suprir as necessidades e garantir os direitos constitucionais dessa parcela crescente da população, principalmente no que se refere a cuidados, conforto ambiental, acessibilidade e lazer. Método: Os procedimentos metodológicos utilizados na pesquisa afim de obter os resultados, se deram inicialmente através de leituras sobre o tema, em busca de embasamento teórico e maior aproximação com as características do público alvo, nesse caso os idosos. Resultados e discussão: A população idosa vem crescendo a cada ano, influenciado pelos avanços da medicina, o crescimento populacional de idosos no Brasil poderá atingir o número de 30 Milhões de idosos até a segunda década do século XXI, segundo o Instituto Brasileiro de Geografia e estatística (IBGE). Seguido desse crescimento, tem-se uma sociedade diferente a de décadas atrás; atualmente, a mulher que antes era responsável por cuidar dos filhos e dos membros mais velhos da família encontra-se inserida no mercado de trabalho, reduzindo o tempo disponível a se dedicar aos cuidados dos familiares idosos. É nesse novo contexto que o idoso passa a necessitar de local para cuidados e abrigo. A presente pesquisa, trata então do tema

\footnotetext{
${ }^{1}$ Graduado em Arquitetura e Urbanismo pela Faculdade Santa Maria, Cajazeiras, Paraíba.

2 Docente da Faculdade Santa Maria, Cajazeiras, Paraíba.

${ }^{3}$ Docente da Faculdade Santa Maria, Cajazeiras, Paraíba.

4 Docente da Faculdade Santa Maria, Cajazeiras, Paraíba.

5 Docente da Faculdade Santa Maria, Cajazeiras, Paraíba.

${ }^{6}$ Docente da Faculdade Santa Maria, Cajazeiras, Paraíba.
} 
Instituição de Longa permanência (ILPI) como opção para cuidados e lugar para os idosos viverem essa fase da vida. Os dados sobre os idosos, e sobre as duas instituições usadas na pesquisa como objeto de estudo, serão obtidos através da aplicação de entrevista, visitas in loco e levantamento fotográfico. Por meio da pesquisa pretende-se obter informações suficientes para elaborar um programa de necessidades a ser aplicado em um anteprojeto arquitetônico de uma ILPI na cidade de São José de Piranhas-PB. Conclusão: Entende-se que um projeto pensado para o bem-estar das pessoas deve buscar harmonizar a técnica a outras características que despertem em seus usuários um sentimento de pertence, de apego ao lugar, e isso só é possível quando se projeta de forma honesta as necessidades e anseios do público alvo, pois a arquitetura deve ser feita para as pessoas, sem as pessoas a arquitetura seria inútil.

Descritores: Conforto Ambiental. Idosos. Envelhecimento populacional. Instituição de Longa Permanência para Idosos.

ABSTRACT: The elderly population is growing every year, influenced by the advances in medicine, according to the Brazilian Institute of Geography and Statistics (IBGE), the population growth of the elderly in Brazil can reach 30 million aged people by the second decade of the 21st century. Following this growth, we have a different society from decades ago; the women who were formerly responsible for caring for the children and the older members of the family is now in the labor market, thereby the time available to care for elderly relatives is reduced. In this new context, the elderly need a place for care and shelter. The present research deals with the theme Long-Stay Institution for Elderly People as an option of a place for the elderly to live this phase of their lives. The aim of this study is to analyze the current situation of the elderly who need a place-to-live alternative, as well as to understand how the LSIFP can meet the needs and guarantee the constitutional rights of this growing part of the population, especially with regard to care, environmental comfort, accessibility and leisure. The methodological procedures used in this research in order to obtain the results were given through lectures on the subject, searches of theoretical basis and closer approximation with the characteristics of the target public, in this case the elderly. The data on the elderly and on the two institutions used in the research as the object of the study will be obtained through the application of interviews, site visits and photographic surveys. This research intends to obtain enough information to elaborate a needs program to be applied in an architectural project of an LSIFP in the city of São José de Piranhas-PB.

Descriptors: Population-ageing. Long-term Institution for the Elderly. Environmental Comfort. Aged. 


\section{INTRODUÇÃO}

De acordo com Instituto Brasileiro de Geografia e Estatística - IBGE (2010), assim como em todo o mundo, a população idosa no Brasil vem crescendo nos últimos anos, isso graças às novas tecnologias direcionadas principalmente à área de saúde, bem como a outros fatores ligados a baixa taxa de natalidade. Esse fator, traz então, um aumento da população idosa em relação à população jovem, logo tratar do tema envelhecimento populacional relaciona-se diretamente com questões de cuidados ao idosos.

Segundo o Instituto de Pesquisa Econômica Aplicada (IPEA), grande parte dessa população ao atingir idade entre 60 anos ou mais, encaixa-se em uma nova realidade social, na qual as famílias e a sociedade se encontram atualmente em configurações diferentes as de anos atrás. A exemplo disso, a mulher que antes era responsável por cuidar dos filhos e dos mais velhos, atualmente se encontra inserida no mercado de trabalho, comprometendo o tempo que seria disponibilizado aos cuidados com os idosos da família.

Para tanto, ainda que por lei, o suporte de amparo e cuidados aos idosos seja designado à família como determina a Constituição Federal (BRASIL, 1988) em seu artigo 230, nem sempre isso ocorre. Dessa forma, esse apoio aos idosos cada vez mais tem sido direcionado à alternativas de cuidados de longa duração, que provêm da expressão inglesa long term care (cuidados contínuos), tendo como a mais conhecida e talvez mais antiga dessas alternativas, as Instituições de Longa Permanência para Idosos, ILPIs, atual denominação para os antigos asilos.

Embora não exista uma definição única para ILPIs, Camarano e Kanso (2010) afirmam que essas instituições costumam ser denominadas como ambientes de cuidados e moradia para os idosos que não possuem esse suporte por parte da família.

No entanto, as instituições não são buscadas apenas por familiares ou idosos que não possuem suporte de cuidados ou condições de morar sozinhos. Segundo 
Lima, Medeiros e Nobrega, (2015), alguns idosos tomam por si próprios a decisão de ir morar em instituições por julgarem um ambiente destinado às suas necessidades e sua faixa etária.

Esse estudo trata do tema ILPIs como alternativa de lugar para os idosos viverem essa fase da vida, embora haja várias outras alternativas, as repúblicas, casa lar, centro de convivência, centro dia; as ILPIs ainda são as mais buscadas e mais conhecidas dentre essas, por se tratarem de instituições mais completas, pois segundo a Agência Nacional de Vigilância Sanitária (ANVISA) as ILPIs são consideradas instituições híbridas, que oferecem moradia, cuidados e alguns serviços de saúde.

A ANVISA diz ainda que esse tipo de instituição deve fazer parte da infraestrutura de qualquer cidade de médio e grande porte. Assim, de acordo com essas informações, para um maior aprofundamento do tema, buscou-se conhecer uma determinada ILPI na cidade de São José de Piranhas, na Paraíba, pelo fato de se saber que essa unidade funciona numa residência, ou seja, em um local improvisado e que, precisa ser investigado para se saber se atende às demandas de uma ILPI.

Logo, tem-se como objetivo, analisar o ambiente físico e o funcionamento dessa instituição, a fim de encontrar resultados que possam afirmar se a ILPI atende as necessidades dos seus residentes em quesitos como conforto, lazer, privacidade, acessibilidade; e se elas proporcionam atividades que incentivam as relações sociais entre os próprios residentes e também com pessoas externas à instituição.

Estudar sobre o tema, justifica-se pela necessidade existente e crescente em relação à busca por alternativas de cuidados aos idosos, parcela essa que continuará a crescer como afirmam as pesquisas já citadas.

Portanto, conhecer de forma mais detalhada alternativas de cuidados aos idosos, nesse caso as ILPIs, possibilita a proposição de soluções e melhorias baseadas em normativas, leis e nas necessidades reais acerca desse tipo de instituição. Além de focar nesse grupo de pessoas, e talvez assim, fazer com que como alternativa mais procurada, as ILPIs venham a ser a melhor dentre as opções de moradia para os idosos. 
A escolha de São José de Piranhas como local para aplicar os resultados obtidos, deu-se por se tomar conhecimento de que na cidade já existe uma ILPI, porém, esta funciona em um ambiente adaptado como será mostrado posteriormente.

Mediante as estimativas de que a população idosa continuará crescendo no Brasil como um todo, presumir-se que futuramente, uma ILPI apenas, não irá comportar a demanda da população idosa de São José de Piranhas, percebe-se então a importância de se preparar para atender essa demanda prevista, propondo com base nas pesquisas, um programa de necessidades a ser aplicado em um anteprojeto arquitetônico de uma ILPI que atenda de forma mais adequada as necessidades daqueles que precisarão buscar essa modalidade de instituição como lugar para viver.

O estudo justifica-se pelo fato de existir uma ILPI que funciona de forma adaptada em duas residências germinadas na cidade de São José de Piranhas, viuse então a necessidade de propor um ambiente mais adequado as necessidades presentes e demandas futuras. Com base nisso a pesquisa objetiva elaborar um anteprojeto de arquitetura de uma ILPI na cidade de São José de Piranhas; considerando quesitos de conforto ambiental, lazer e acessibilidade, no intuito de tornar o ambiente institucional mais inclusivo e acolhedor.

\section{MÉTODO}

A presente pesquisa, visa a tratar os resultados de forma qualitativa e quantitativa, os procedimentos utilizados para o trabalho se deram através de pesquisa bibliográficas para se obter um conhecimento mais aprofundado em relação ao objeto de estudo, onde foram buscadas informações sobre a histórias das ILPIs no Brasil, o crescimento da população idosa, institucionalização dos idosos, conceitos de ILPI, normas para o funcionamento de uma ILPI, dentre outros presentes no decorrer do trabalho. A metodologia de coleta de dados foi realizada por meio de levantamento fotográfico, ficha de observação e também através de 
entrevista semiestruturada direcionada aos funcionários da ILPI usada para estudo de campo, e aos idosos da mesma. Os critérios de inclusão e exclusão restringiramse as pessoas que trabalham ou residem na instituição visitada para estudo. Os dados obtidos foram tratados em forma de gráficos e imagens e quando necessários feitos croquis dos ambientes da ILPI utilizadas como estudo de campo, a pesquisa foi realizada entre outubro de 2018 e junho de 2019.

A amostra da pesquisa são idosos com idade igual ou superior a 60 anos, dos sexos masculino e feminino, institucionalizados em uma ILPI de São José de Piranhas, bem como funcionários que trabalham na Instituição, sendo um desses funcionários o administrador e os demais, na função de cuidadores dos idosos e auxiliares de serviços.

O estudo foi fundamentado em uma indagação que se questiona: as ILPIs não são clinicas, e sim um lugar para morar na fase idosa, portanto é necessário entender como esses ambientes podem ser melhorados para cumprir a função não só de cuidados de saúde, mas principalmente a de moradia, partindo desse pressuposto, como a arquitetura pode contribuir no intuito de potencializara as características positivas das instituições ou propor soluções que as tornem um lugar melhor para viver?

O presente trabalho seguiu os seguintes procedimentos para se chegar a obtenção dos resultados pretendidos:

- A primeira etapa se deu através pesquisas em livros e trabalhos científicos, buscando-se um referencial teórico que embasaram o início do trabalho e permitiu um maior aprofundamento em relação ao tema abordado;

- A segunda etapa consistiu no primeiro contato com o objeto de estudo, nesse caso a ILPI utilizada como estudo de campo na cidade de São José de Piranhas. Nesse momento o responsável pela instituição foi contatado, para através do termo de anuência e de corresponsabilidade, ter-se acesso a Instituição através de visitas necessárias para coleta dos dados, bem como acordar a autorização para o uso dos dados obtidos;

- A terceira etapa, se deu através de visitas in loco, no intuito de fazer anotações utilizando o método de observação simples, que segundo Zanelli (2002), é um procedimento que traz o pesquisador para o cenário de estudo, descrevendo 
suas principais características em relação ao espaço físico e seu funcionamento relacionado aos indivíduos que fazem uso deste cujos dados devem ser anotados na ficha de observação. "A observação atenta dos detalhes põe o pesquisador dentro do cenário, para que possa compreender a complexidade dos ambientes psicossociais, ao mesmo tempo em que the permite uma interlocução mais competente" (ZANELLI, 2002, p.830).

- A quarta etapa se deu por meio de levantamento fotográfico que de acordo com Balomenou e Garrod (2015), consiste na utilização de fotos para complementar o que foi escrito; por meio desse método é possível tornar mais objetivas as informações que se deseja passar, por meio desse procedimento foram feitas as análises em relação ao objeto de estudo destacando suas características referentes aos espaços que o compõem, outras como acessibilidade, lazer e conforto ambiental relacionado a iluminação e ventilação dos ambientes;

- $\quad \mathrm{Na}$ quinta etapa, após os participantes da pesquisa, (idosos e funcionários da ILPI) assinarem os termos de consentimento livre e esclarecido, posteriormente foi aplicada a entrevista semiestruturada que consiste segundo Boni e Quaresma (2005), em um tipo de entrevista cujo as questões são predefinidas, mas que dão maior liberdade de respostas e se conectam a outras questões que podem ser levadas como uma conversa informal.

Segundo BONI e QUARESMA (2005, p.75):

As técnicas de entrevista aberta e semiestruturada também têm como vantagem a sua elasticidade quanto à duração, permitindo uma cobertura mais profunda sobre determinados assuntos. Além disso, a interação entre o entrevistador e o entrevistado favorece as respostas espontâneas.

\section{RESULTADOS E DISCUSSÃO}

Diante do novo contexto social no qual a população idosa está atualmente inserida, cujo âmbito familiar tem se distanciado como recinto de permanência e 
cuidados aos idosos, surge a necessidade de averiguar quais as alternativas que suprem as necessidades dessa parcela da população, que segundo o IBGE (2010) continuará crescendo nos próximos anos.

Assim, baseando-se nos estudos abordados até então, avaliou-se 0 funcionamento da Instituição Lar dos Idosos Cirilo Pereira de Alencar na cidade de São José de Piranhas, quanto à realização das AVDs, cuidados com a saúde, suporte às necessidades físicas, questões de conforto ambiental, entre outros aspectos obtendo-se os seguintes resultados.

\section{Acessibilidade}

O terreno em que se encontra a Instituição é semi-plano, o que possibilita uma melhor mobilidade no acesso aos diferentes níveis dos pisos, que não apresentam diferenças de alturas nas transições dos ambientes, uma vez que essa característica possibilita uma circulação mais fluida e com menos riscos de acidentes.

Em relação às aberturas das portas, algumas encontram-se dentro dos padrões de medidas mínimos estabelecidos pela NBR9050 (ABNT 2015), que determina um vão livre de pelo menos $80 \mathrm{~cm}$, dimensões estas que possibilitam a passagem de uma cadeira de rodas por exemplo.

Embora a maioria das portas estejam conforme determina a norma NBR9050 (ABNT 2015), a posição em relação à abertura não se adequa às normas, visto que essas devem abrir para o lado de fora dos ambientes, o que não ocorre na edificação por se tratar de um espaço que não foi originalmente projetado conforma as normas de acessibilidade vigentes.

Para o auxílio da mobilidade e acessibilidade em um ambiente, alguns equipamentos devem estar presentes, a exemplo de equipamentos como barras de apoio, corrimãos, piso tátil, entre outros.

Dos equipamentos citados na norma, identificou-se apenas o elemento das barras de apoio localizado em um dos banheiros que foi colocado de forma 
inadequada sem os padrões da norma, mas que ainda assim auxilia no uso do ambiente segundo o relato de um dos cuidadores.

Quanto ao layout do mobiliário, este foi definido de forma a acomodar um maior número de idosos por dormitório, porém essa disposição limita os espaços de circulação mínimo para locomoção de idosos acometidos por limitações físicas.

Segundo a NBR9050 (ABNT, 2015) entre as camas deve haver um espaço de pelo menos $90 \mathrm{~cm}$ em quartos coletivos, o que possibilita a aproximação de uma cadeira de rodas para que o usuário tenha acesso ao mobiliário, além de espaço de 1,5 m de diâmetro para o giro da cadeira de rodas, dando acesso ao ambiente em várias direções, o que não ocorre em vários ambientes da Instituição.

Os pontos mais críticos referentes aos espaços de mobilidade, encontram-se no ambulatório que funciona junto com a diretoria; na disposição do mobiliário de alguns quartos; nos banheiros que não possuem espaço mínimo para a acesso em cadeira de rodas; e na cozinha utilizada para as atividades de preparo dos alimentos, que também serve de espaço para refeições.

Pode-se perceber que devido à falta de espaço, alguns ambientes como por exemplo o quarto tem parte do seu mobiliário utilizado para acomodar objetos provenientes de doações.

\section{Conforto ambiental: Iluminação e ventilação natural}

Em relação ao conforto ambiental, levando-se em consideração aspectos como o aproveitamento de iluminação e ventilação natural, os ambientes de longa permanência como os quartos dos idosos por exemplo, possuem aberturas paras as áreas externas.

Nos ambientes em que a ventilação é insuficiente, esta é suprida através do uso de ventiladores. Embora o posicionamento das janelas não seja adequado à direção da ventilação predominante no local (sudeste), o fato dos quartos possuírem janelas já é visto como uma vantagem por se tratar de residências geminadas em ambos os lados. 
Sobre a iluminação natural, essa se dá por meio das janelas e portas presentes nos ambientes, sem a presença de qualquer outro elemento arquitetônico voltado a essa necessidade que é de suma importância. Segundo Hazin (2012) a iluminação do ambiente traz benefícios fisiológicos e psicológicos para as pessoas, proporcionando a realização de suas atividades nesses ambientes em um ritmo biológico devido a percepção das fazes do dia através da luz natural.

\section{Lazer}

A Instituição não dispõe de espaço de lazer, logo é na sala de estar, que os idosos interagem entre si, assistindo TV e partilhando de conversas.

A sala é um espaço simples, que mantém as mesmas características de uma sala comum de uma residência, com mobiliário disposto de forma a acomodar seis pessoas.

Outro espaço utilizado pelos idosos da instituição durante parte do dia, é a varanda que tem vista para rua, devido estar localizada na entrada da instituição. Esse espaço acaba permitindo que os idosos tenham um contato visual com a área externa e com a dinâmica natural que acontece naquele espaço.

Por se tratar de um espaço pequeno, adaptado em duas residências, concluise, mediante as entrevistas realizadas, observações e levantamento fotográfico, que as principais dificuldades em relação ao ambiente são relacionadas às dimensões, o que acaba gerando problemas em relação à acessibilidade e à realização das atividades diárias na instituição, sejam estas atividades de serviços ou simplesmente as atividades diárias dos idosos.

Constatou-se também, que a inexistência de espaços para lazer ou outras atividades ocupacionais, além de ser um dos principais anseios dos idosos e dos funcionários, faz com que eles passem muito tempo ociosos na instituição, pois ambientes com propostas para lazer segundo Giraldi (2014) é importante para fazer o idoso aproveitar com prazer e conforto a fase pós trabalho, definida assim como o 
momento em que o indivíduo se aposenta e tem mais tempo disponível para disfrutar dessas atividades.

\section{CONSIDERAÇÕES FINAIS}

O crescente aumento da população idosa em um contexto social cujas famílias vem diminuído, e juntamente com esse fator diminui-se também os membros com tempo disponível para cuidar dos idosos, demanda a busca por alternativas que venham a suprir essas necessidades.

As ILPIs surgem como uma das principais alternativas por se tratar de uma modalidade de instituição que oferece abrigo e cuidados em tempo integral aos idosos; mediante as informações obtidas por meio deste trabalho, pode-se afirmar que a arquitetura tem um papel fundamental nesse assunto, visto que uma das suas principais funções é o bem-estar das pessoas, e que lugar melhor para se tratar de bem-estar se não em uma instituição destinada a pessoas idosas.

Em meio as pesquisas acerca das normas, e demais parâmetros que devem ser seguidos para se projetar um ambiente, é de fundamental importância concebêlo levando em consideração aspectos além do que ditam as normas. Portando esse anteprojeto propõe ambientes no intuito de desmistificar os conceitos de que uma ILPI é um lugar ruim para se viver.

Através dos ambientes, a proposta aqui apresentada, busca distanciar a Instituição da imagem de ambiente de confinamento, dessa forma, os espaços propostos apresentam características ligadas ao conceito de liberdade, por meio da integração dos ambientes, seja de forma visual, usando aberturas envidraçadas, e elementos vazados; ou de forma mais direta, através de grandes aberturas e ausência de paredes quando possível, fazendo o interior se misturar com o exterior, ampliando os espaços de vivência dentro da instituição, tentando assim, trazer para os indivíduos, um ambiente social, que se assemelhe ao que se tem em sociedade fora do ambiente institucional. 
É necessário entender de que forma a arquitetura pode contribuir ou auxiliar as pessoas em suas particularidades e limitações, dessa forma pensar no ambiente construído levando em consideração que o processo de envelhecimento segundo Mendes e Côrte (2009) está diretamente ligado com a diminuição das capacidades de raciocínio e físicas dos indivíduos e suas capacidades de interação aos estímulos do ambiente. Mediante essa informação, demanda-se que a arquitetura projete de forma a buscar soluções para aqueles que fazem uso dos espaços edificados.

Para que a arquitetura consiga cumprir um papel relevante para os indivíduos com capacidade cognitiva reduzida como é o caso das pessoas acometidas por Alzheimer por exemplo, deve-se fazer uso de elementos como cores, que segundo Sousa e Maia (2013) neste caso servem de referência para localização nos ambientes, deve-se fazer uso também de equipamentos e materiais que garantam melhor usabilidade e segurança dos ambientes como pisos antiderrapantes, corrimãos, sinalização adequada, barras de apoio dentre outros elementos para estes fins.

A proposta do anteprojeto visa a dispor um modelo arquitetônico de instituição que sirva de referência para outras implantações da mesma modalidade em outras cidades, no intuito de prover mais conforto e inclusão aos idosos institucionalizados.

É um grande desafio, porém necessário, pensar em ambientes que ao mesmo tempo que estejam tecnicamente em harmonia com normas e diretrizes, possam se tornar acolhedores para pessoas que chegam até estes com uma história de vida, lembranças, laços sentimentais distanciados e muitas das vezes rompidos; é nesse tocante que além da arquitetura, deve-se em comunhão com o espaço projetado, ter- se o trabalho de pessoas que possam tornar o ambiente institucional mais humanizado e não apenas um lugar para morar.

Entende-se então, que um projeto pensado para o bem-estar das pessoas deve buscar harmonizar a técnica a outras características que despertem em seus usuários um sentimento de pertence, de apego ao lugar, e isso só é possível quando se projeta de forma honesta as necessidades e anseios do público alvo, pois a arquitetura deve ser feita para as pessoas, sem as pessoas a arquitetura seria inútil. 


\section{REFERÊNCIAS BIBLIOGRÁFICAS}

ARAÚJO, Claudia Lysia de Oliveira; SOUZA, Luciana Aparecida de; FARO, Ana Cristina Mancussi e. Trajetória das instituições de longa permanência para idosos no Brasil. Hist. Enferm. Rev. Eletrônica, São Paulo, p.250-262, dez. 2010. Disponível em:<http://bases.bireme.br/cgibin/wxislind.exe/iah/online/?lsisScript=iah/iah.xis\&src=google\&ba se $=B D E N F \& l a n g=p \&$ nextAction $=\mid n k \&$ exprSearch $=25611$ \&indexSearch $=I D>$. Acesso em: 01 out. 2018.

ARENDT, Ana Paula Penso. Exigências de habitabilidade da ABNT NBR 15575: Uma análise comparativa em projetos arquitetônicos. 2015. 89 f. TCC (Graduação) - Curso de Engenharia, Departamento Acadêmico de Construção Civil Curso Superior de Engenharia Civil, Universidade Tecnológica Federal do Paraná, Pato Branco, 2015. Disponível em: $<$ http://repositorio.roca.utfpr.edu.br/jspui/bitstream/1/6150/1/PB_COECI_2015_2_21. pdf>. Acesso em: 14 mar. 2019.

BALOMENOU, N.; GARROD, B. (2015). A review of participan-generated image methods in the social sciences. Journal of mixed methods research. doi: 10.1177/1558689815581561.

BARBOSA, Ana Lúcia de Góes Monteiro. Conforto e qualidade ambiental no habitat do idoso. 2002. 148 f. Dissertação (Mestrado) - Curso de Arquitetura Universidade Federal do Rio de Janeiro, Rio de Janeiro, 2002. Disponível em: <https://pantheon.ufrj.br/handle/11422/3773>. Acesso em: 12 nov. 2018.

BIANCHI, Silva Alves. Qualidade do Lugar nas Instituições de Longa Permanência para Idosos Contribuições Projetuais para Edificações na Cidade do Rio de Janeiro. 2013. 294 f. Tese (Doutorado em Arquitetura) - Universidade Federal do Rio de Janeiro. Rio de Janeiro, 2013. Disponível em: <https://docplayer.com.br/10259444-Qualidade-do-lugar-nas-instituicoesde-longa- permanencia-para-idosos-contribuicoes-projetuais-para-edificacoes-na-cidade-do riode-janeiro.html >. Acesso em: 10 nov. 2018.

BONI, Valdete; QUARESMA, Silvia Jurema. Aprendendo a entrevistar: como fazer entrevistas em Ciências Sociais. Revista Eletrônica dos Pós-graduandos em Sociologia Política da UFSC, Santa Catarina, n. 1, p.68-80, jan. 2005. Disponível em: <https://periodicos.ufsc.br/index.php/emtese/article/view/18027/16976>. Acesso em: 04 maio 2019.

BRASIL. Ministério da Saúde. Portaria no 810, de 22 de setembro de 1989. Normas e os padrões para o funcionamento de casas de repouso, clínicas geriátricas e outras instituições destinadas ao atendimento de idosos, a serem observados em todo o território nacional. Diário Oficial [da] União, Brasília, DF, 27 set. 1989. Seção 1, p. 17.297-17.298.

CAMARANO, Ana Amélia; KANSO, Solange. As instituições de longa permanência para idosos no Brasil. Revista Brasileira de Estudos de População, Rio de Janeiro, p.233-235, jan. 2010.

CAMARANO, Ana Amélia. Características das Instituições de Longa Permanência para Idosos Região Nordeste. Rio de Janeiro: Ipea, 2008. 348 p.

CDHU. Programa Vila Dignidade. 2019. Disponível em: $<$ http://www.cdhu.sp.gov.br/web/guest/perguntas-frequentes/programa-vila- dignidade>. Acesso em: 28 mar. 2019.

CHRISTOPHE, Micheline. Instituições de Longa Permanência para Idosos no Brasil: uma 
opção de cuidados de longa duração? 2009. 178 f. Dissertação (Mestrado em Estudos Populacionais e Pesquisas Sociais) - Escola Nacional de Ciências Estatísticas. Rio de Janeiro, 2009.

COSTA, Maria Carla N. S.; MERCADANTE, Elizabeth Frohlich. O Idoso residente em ILPI (Instituição de Longa Permanência do Idoso) e o que isso representa para o sujeito idoso. Revista Kairós Gerontologia, São Paulo, p.209-222, mar. 2013.

FERREIRA, Mario dos Santos. Ergonomia do envelhecimento: acessibilidade e mobilidade urbana no Brasil. Ergo design \& Hci, Rio de Janeiro, v. 4, n. 1, p.31-39, nov. 2016.

Lima, M.A.X.C. (2005). O fazer institucionalizado: O cotidiano do asilamento. Dissertação de mestrado. São Paulo (SP): PEPGG/PUC-SP.

MAIOR, Idade. Programa vila dignidade. 2018. Disponível em: <https://www.idademaior.com.br/fatos-direitos-1-maio.html>. Acesso em: 26 mar. 2019.

NOT, Guilherme. A importância da acessibilidade para idosos. 2018. Disponível em: <https://tecnosenior.com/acessibilidade-para-idosos/>. Acesso em: 14 nov. 2018.

NOVAES, Regina Helena Lasneaux. Os asilos de idosos no Estado do Rio de Janeiro Repercussões da (não) integralidade no cuidado e na atenção à saúde dos idosos. Dissertação (Mestrado em Saúde Coletiva) - Instituto de Medicina Social, Universidade do Estado do Rio de Janeiro/UERJ, 2003.

PERLINI, N.; LEITE, M.; FURINI, A. Em busca de uma instituição para a pessoa idosa morar: motivos apontados por familiares. Revista da Escola de Enfermagem da USP, v. 41, n. 2, p. 229-236, 1 jun. 2007.

SOUSA, Isabella Gaspar; MAIA, Ivana Márcia Oliveira. Arquitetura de interiores em ambientes para idosos portadores da doença de Alzheimer. Arq. urb, São Paulo, n11, p.200-202, mar. 2014.

VAZZOLLÉR, Josélia Barros de Medeiros. Instituição de longa permanência para idosos: privacidade, identidade e conforto. 2015. 118 f. TCC (Graduação em Arquitetura e Urbanismo) Universidade Vila Velha. Vila Velha, 2015. 